\title{
Design of System for Evaluating and Sorting Products with Tools of Statistical Process Control
}

\author{
Stella Hrehová ${ }^{1}$, Erika Fechová ${ }^{2}$ \\ stella.hrehova@tuke.sk, erika.fechova@tuke.sk \\ Faculty of Manufacturing Technologies with seat in Presov, Technical Univer- \\ sity in Kosice, Bayerova 1, 08001 Presov, Slovakia ${ }^{1}$ \\ Faculty of Manufacturing Technologies with seat in Presov, Technical Univer- \\ sity in Kosice, Bayerova 1, 08001 Presov, Slovakia ${ }^{2}$
}

\begin{abstract}
An important aspect of the company's position on the market is its ability to declare and maintain the required level of production quality. The most widely used way of evaluating the achieved quality level is the tools and methods of statistical process control. The combination of these tools and current technologies to automated data collection enables a design of a system that would be able not only to graphically present the data of the monitored parameters but also to evaluate them. In the presented design of system is also considered a database block, whose task is to archive the results. Linking the database to the proposed system aims to assess the level of production quality achieved over the long term.
\end{abstract}

Keywords: quality; system; presentation;

\section{Introduction}

Statistical Process Control (SPC) is a time honored and well demonstrated method of process management. SPC has long been used for measuring and monitoring quality by the quality departments and labs of most industrial manufacturing facilities. SPC has undergone periodic recasting and updates, such as Continuous Process Improvement (CPI) and Total Quality Management (TQM). Certainly SPC is a key part of the Six Sigma and Lean Six Sigma processes that many manufacturing companies have invested in [1].

SPC is a set of tools to monitor the stability of the manufacturing process and improve its capability by reducing process variability. The theory of Walter A. Shewhart, who developed the design of the regulation charts, became the basis for the evaluation of the quality of the production process and they became an important 
tool for improving production [2]. This theory is based on the existence of parameter variability in the production process, which is influenced by a number of influences. The result is that it is impossible to make two completely identical products. In the production process are specified so called control limits [3]. Their overshoot may indicate an undesirable effect, which may result in a poor quality of product. For a certain number of exceedances of control limits it is advisable to perform an analysis of the causes that caused this condition in a particular arrangement.

If the production process is evaluated as stable and no exceedances of the control limits are recorded, the indices of capability are calculated. These indices evaluate process with numerical values. In order for the process to be evaluated as eligible, the values of these indices must be at specified intervals. For each further evaluation of the same process parameters, control limits and indices values are taken as the basis for comparing the measured data.

\subsection{Indices of capabilities}

Process capability indices are used in the manufacturing industry to provide numerical measures on whether a process is capable of producing items within the predetermined specification limits [3]. The capability indices or process capability ratio is a statistical measure of process capability produce output within specification limits. The concept of process capability only holds meaning for processes that are in a stabile state. Process capability indices measure how much "natural variation" a process experiences relative to its specification limits and allows different processes to be compared with respect to how well an organization controls them [4].

$\mathrm{Cp}$ index (the process capability index) compares the required tolerance limits with natural tolerance limits of a process. It indicates what the process would be like if it were centered. It is assumed normal distribution.

$$
\mathrm{Cp}=(\mathrm{USL}-\mathrm{LSL}) / 6 \sigma
$$

where $\sigma$ is the standard deviation of the process,

USL - upper specification limit,

LSL - lower specification limit.

Cpk index is an indicator of current capability of the process. It responds to the deviation of the mean volume of the process from the centre of the tolerance interval, eventually from the target value of the reference indicator of quality.

$$
\mathrm{Cpk}=\min \{(\mathrm{USL}-\mu) / 3 \sigma ;(\mathrm{LSL}+\mu) / 3 \sigma\}
$$

where $\mu$ is the arithmetic mean of the measured values. 
Cases, which can explain the relationship between $\mathrm{Cp}$ and $\mathrm{Cpk}$, are given below [5]:

- If $\mathrm{Cp}=\mathrm{Cpk}$, the process is centered at the midpoint of the specification limits.

- If $\mathrm{Cpk}<\mathrm{Cp}$, the process if off centered. This can be accepted as lower capability than the case that the process is centered. The reason is that it is not operating at the midpoint of the interval between the specification limits.

- If $\mathrm{Cpk}=0$, the process mean is exactly equal to one of the specification limits.

- If $\mathrm{Cpk}<0$, the process mean lies outside the specification limits, that is for $\mu>\mathrm{USL}$ or $\mu<\mathrm{LSL}, \mathrm{Cpk}<0$.

- If $C p k<-1$, the entire process lies outside the specification limits. It should be noted that some authors define Cpk to be nonnegative so that values less than zero are defined as zero.

$1<\mathrm{Cpk}<1.33$ means that the process is barely capable. Automotive industry uses $\mathrm{Cpk}=1.33$ as a benchmark in accessing the capability of a process.

The index $\mathrm{K}$ indicates that if the required target process is not identical with the centre of the tolerance range than it captures the mean deviation from the desired value $\mathrm{T}$, which is very important information [6].

$$
\mathrm{K}=(2|\mathrm{~T}-\mu| /(\mathrm{USL}-\mathrm{LSL}))
$$

It may occur

- $\mathrm{K}=0$ - the mean value of the process is identical to the desired target value,

- $0<\mathrm{K}<1-$ mean the process is within tolerance limits,

- $\mathrm{K}>1$ - the mean value of the process is out of the tolerance limits.

\subsection{Graphical representation}

Graphical representation of measured data is an important element of evaluating of process quality. Its advantage is the immediate visual interpretation of the measured data. The points are plotted on an $\mathrm{x} / \mathrm{y}$ axis with the $\mathrm{x}$-axis usually representing time. The plotted points are usually averages of subgroups or ranges of variation between subgroups, and they can also be individual measurements. Some additional horizontal lines representing the average measurement and control limits are drawn across the chart [7].

\subsubsection{Histogram}

In the quality applications, histograms are well-known as one of the seven basic tools of quality control. Histograms are very useful in estimating process capability 
and for visualizing process performance. Hence, histograms can be used to determine the reason for poor process performance, instantaneously. As quality characteristics are often assumed to have normal distribution, histogram along with the sample mean and sample standard deviation can provide information about process capability as it is possible to estimate the process capability independent of the specifications.

The shape of histogram, which is common both in nature and industrial settings presents Figure 1.

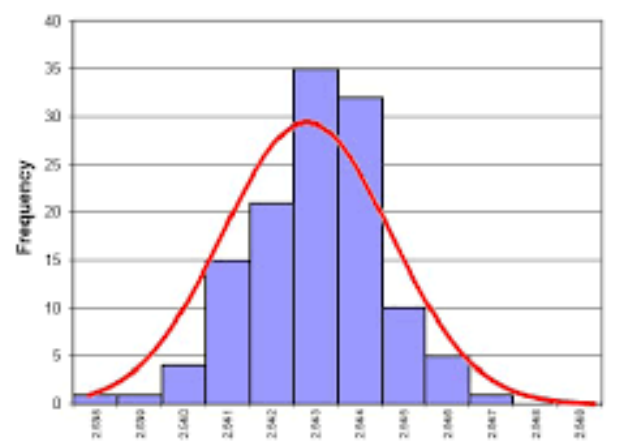

Fig. 1. Histogram

If the histogram is fairly skewed, then the normality assumption might be a concern and estimate of the process capability is unlikely to be correct. On the other hand, there are some drawbacks of using histograms. Fundamentally, it is necessary to divide the range of a variable into classes. Also, histograms cannot be used for small samples, for this reason, at least hundred observations are needed. Essentially, in order to have reliable estimate of process capability, these observations must be moderately stable [8].

\subsubsection{Control charts}

Control charts typically display the limits that statistical variability can explain as normal. It graphical represents how a process changes over time. This graph is based upon the Central Limit Theorem which tells us, in effect, that the samples will follow a normal distribution regardless of the shape of the parent distribution. If the process is performing within considered limits, it is said to be in control; if not, it is out of control. Data are plotted in time order. A control chart has a central line for the average, an upper line for the upper control limit (UCL) and a lower line for the lower control limit (LCL) [3]. In practice, specification limits USL and LSL are usually established by engineers and are not a function of the capabilities of the 
process. Control limits represent "what the process can do," and specification limits represent "what we want the process to do" [9]. The general form is showed in Figure 2.

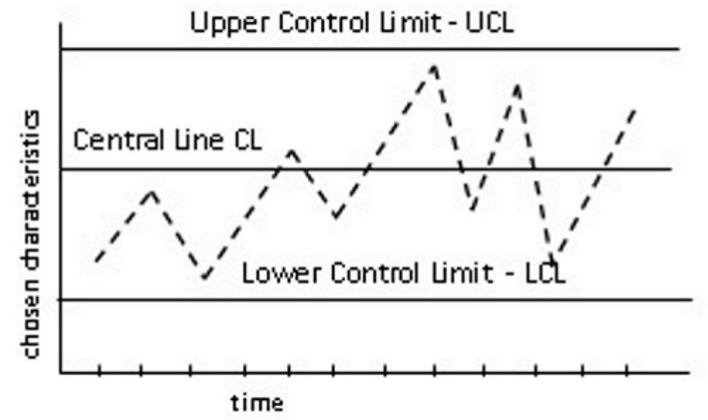

Fig. 2. Scheme of regulation chart

Control charts are also effective as they can illuminate developing trends that may produce a process failure. Based on the graphical display of the measured values, it is possible to capture a state in which the control limits are exceeded in a relatively short time. If this happens more often it is necessary to identify and assess the cause of the condition.

\section{Specifications of database}

The idea to add a database to the proposed system was based on the vision of long-term monitoring and process quality evaluation. Based on an analysis of the requirements that the application should perform, the following tasks are proposed:

- archive the data obtained from the evaluation of the achieved quality level of the monitored parameter,

- verbal evaluation of the achieved level based on SPC qualification index values using fuzzy approach,

- ability to add data, export and print items.

Due to the fact that the data will be used by multiple users, a user interface is provided. It allows perform the required tasks under the authority. The Figure 3 shows a possible form of the described database. 


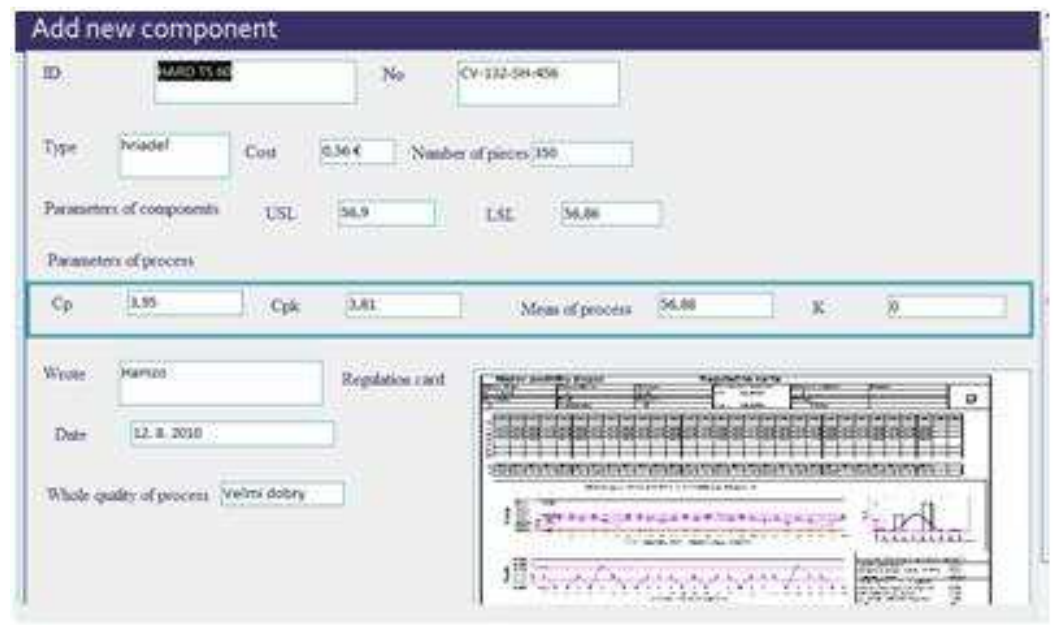

Fig. 3. Design of database

\subsection{Features of fuzzy approach}

The numerical data is not informative for the common user. Using the verbal interpretation of the achieved value, it is possible evaluate the process immediately [10]. To achieve this goal, a fuzzy logic approach has been chosen when it is possible to assign a verbal equivalent based on the set values. Fuzzy inference defines the system behavior by means of the rules of <If > <Then> type at the language level. In these algorithms conditional sentences occur evaluating the condition of a related variable. For each rule it is necessary to determine its weight. The result depends to a certain extend on a correct determination of the defined rules importance. The weight of these rules can be changed during optimization. The result of this process is a linguistic variable. Composition connects all fuzzy sets of outputs into one set for each output. In such a case, a logical OR is used. The aim of defuzzification is to express a crisp value of the given value from the resulting fuzzy set [11].

\section{Description of designed system}

The system assumes an automatic control of the required parameters through suitably selected devices and subsequent writing of these values. In Figure 4 is a schematic design of the system which describes the overall block arrangement and adjustment of the individual parts of the system. 


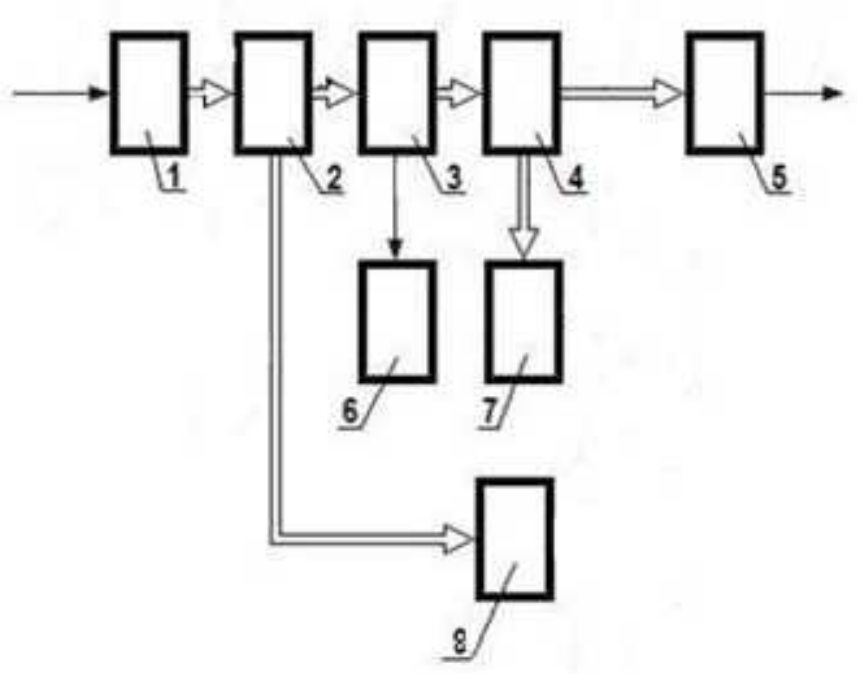

Fig. 4. Design of system

Design of system consists of a measuring module 1 , in which measuring of required prescribed parameters of individual products are carried out. Those proceed in series one after another, while the data on each of them (including the time of measuring) are saved into a parameters block 2. After passing the entire supply, measured data are evaluated by tools of SPC. This statistical data (e.g. mean value, variance, standard deviation, indices of capability, etc.), is compared to predetermined boundary values. In case of exceeding the prescribed allowable limits, the state is indicated by signalling. At the same time the data is moved to a block of product indication 4 . From this block the data on suspect products is transferred into the block 5, which discards suspicious items from the sequence of measured products. From the block of indication of products 4 the data on over-limit products processes to a block of causes analyser 7 , the role of which is to set the causes according to a size and configuration of measured overload of prescribed limits. These results are specified according to knowledge of experts and they can be displayed on the screen.

The measured data of the parameter block 2 is moved to the database block 8 , where the results of evaluation are recorded. The database of thus obtained data allows analysis of individual results even in the longer time period and it provides relevant data for control or evaluation of the achieved quality. 


\section{Conclusions}

The designed system aims to provide the manufacturing operator with real-time SPC derived analysis, presented visually in a simple enough format to quickly identify "out of control" parameters. This real-time presentation of measured data can take the form of graphical presentation using an HMI display or it could be in the form of a specified SPC data collection.

Modern control systems, data collection, and departments generate large volumes of process data. Tightly coupled analytics will make control systems a core component of management decision making and improvement of quality.

\section{References}

[1] 21st Century Process Management Using SPC Based Manufacturing, [Online] https://www.nwasoft.com/resources/information-center/white-paper/21st-century-process-management-using-spc-based-manufacturing

[2] Shewhart W A.: Economic control of quality of manufactured product. New York: Van Nostrand, (1931), [Online] http://weblinkwww.pqm-online.com/assets/files/lib/books /shewhart1.pdf

[3] Mottonen, M., Belt, P., Harkonen, J., Haapasala, H., Kess, P.: Manufacturing Process Capability and Specification Limits. The Open Industrial and Manufacturing Engineering Journal, 1, 29-36, ISSN 1874-1525, (2008) [Online] https://benthamopen.com/contents/pdf/TOIMEJ/TOIMEJ-1-29.pdf

[4] Crossley Mark L.: The desk reference of Statistical Quality methods. Second Edition. ASQ Quality Press, ISBN 978-0-87389-725-9, (2008)

[5] Özlem, S., Hakan, T.: Process Capability and Six Sigma Methodology Including Fuzzy and Lean Approaches, [Online] InTech, ISBN: 978-953- 307-211-1, (2010) [Online] http://www.intechopen.com/books/products-and-services--from-r-d-to-finalsolutions/process-capability-and-six-sigma-methodology-including-fuzzy-and-lean-approaches

[6] Montgomery D. C.: Introduction to Statistical Quality Control, $4^{\text {th }}$ edition, Wiley, New York. (2000)

[7] Introduction to Statistical Process Control Techniques (2007) [Online] http://www.statit.com/services/SPCOverview_mfg.pdf

[8] Montgomery, D. C Statistical Quality Control-A Modern Introduction, $6^{\text {th }}$ edition, Wiley, ISBN 9788126525065, (2010)

[9] Šulc, B., Vítečková, M.: Theory and practice of design of regulatory circuits, ČVUT, ISBN -01-03007-5, (2004)

[10] Hrehova, S., Vagaska, A.: Application of Fuzzy Principles in Evaluating Quality of Manufacturing Process, WSEAS TRANSACTIONS on POWER SYSTEMS, Issue 2, Volume 7, ISSN: 2224-350X , (2012)

[11]Davidova, O. : Diagnose the state of the object using fuzzy logic. In. AUTOMA, Theory for practice, No. 11, pp. 52-55, ISSN 1210-9592, (2001) 